\title{
RELAÇÕES ENTRE INCÊNDIOS EM VEGETAÇÃO E ELEMENTOS METEOROLÓGICOS NA CIDADE DE JUIZ DE FORA, MG
}

\author{
FILLIPE TAMIOZZO PEREIRA TORRES ${ }^{1}$, GUIDO ASSUNÇÃO RIBEIRO ${ }^{2}$, SEBASTIÃO VENÂNCIO \\ MARTINS $^{2}$ E GUMERCINDO SOUZA LIMA $^{2}$ \\ ${ }^{1}$ Universidade Presidente Antonio Carlos - Campus II, Ubá - MG, Brasil \\ ${ }^{2}$ Universidade Federal de Viçosa - Departamento de Engenharia Florestal - Campus Universitário, \\ Viçosa - MG, Brasil \\ torresftp@yahoo.com.br, gribeiro@ufv.br, \\ venancio@ufv.br, gslima@ufv.br
}

Recebido Dezembro 2008 - Aceito Julho 2009

\begin{abstract}
RESUMO
Os incêndios em vegetação geram diversos prejuízos econômicos, paisagísticos e ecológicos. Entretanto, para se estabelecer uma política adequada de prevenção e controle, é necessário conhecer as estatísticas referentes a eles. O objetivo deste trabalho é analisar a influência dos elementos climáticos sobre as ocorrências de incêndios dentro da área urbana do município de Juiz de Fora (MG), no período entre 1995 e 2004. Para isso, foi analisada a correlação entre alguns elementos meteorológicos isolados e as ocorrências de incêndios, bem como a eficiência de alguns índices de predição encontrados na literatura. De acordo com os resultados, a umidade relativa do ar medida às $15 \mathrm{~h} 00 \mathrm{~min}$ apresentou a maior correlação; contudo verificou-se que a utilização de uma variável isolada apresentou um baixo índice de correlação com as ocorrências de incêndio, o que ressalta a importância da utilização de modelos que agrupem duas ou mais variáveis. A utilização desses modelos apresentou o resultado da divisão da variável evaporação pela variável precipitação acumulada como o índice mais eficiente para a área de estudo.
\end{abstract}

Palavras-chave: Incêndios, clima, risco

\begin{abstract}
RELATIONSHIPS BETWEEN VEGETATION FIRES AND METEOROLOGICAL ELEMENTS IN JUIZ DE FORA CITY, MG

Vegetation fires generate several economical, landscaping and ecological damages. However, it is necessary to know the fires occurrence statistics in order to establish an appropriate politics of fire prevention and control. The objective of this paper is to analyze the influence of climatic elements on the occurrences of fires in Juiz de Fora (MG), in the period between 1995 and 2004. For that purpose, the correlation between some isolated meteorological elements and the occurrences of fires were analyzed, as well as the efficiency of some predicting indexes found in the literature. According to the results, the relative air humidity measured at 3:00 p.m. presented the greatest correlation value; however it was verified that the use of a single variable presented a low correlation index with the fire occurrences, emphasizing the importance of using models containing two or more variables. The use of such models showed that the rate of the variables, evaporation and accumulated precipitation, was the most efficient index for the study area.
\end{abstract}

Keywords: Fire, weather, risk 


\section{INTRODUÇÃO}

Segundo Nunes (2005), existem dois tipos de fatores determinantes do grau de perigo de incêndio: os fatores constantes, tais como o tipo de material combustível, tipo de floresta e o relevo, e os fatores variáveis, entre os quais a umidade do material combustível e as condições climáticas, tais como a velocidade e a direção do vento, a umidade relativa, a temperatura, o ponto de orvalho, a precipitação e a instabilidade atmosférica.

Nunes et al (2006) afirmam que a ocorrência e propagação dos incêndios em vegetação estão associadas às condições climáticas ou fatores climáticos. A intensidade de um incêndio e a velocidade com que ele avança, estão diretamente ligadas à umidade relativa, temperatura do ar e precipitação. A possibilidade de ocorrência, bem como, a frequência dos incêndios estão relacionadas às condições atmosféricas locais. Dessa forma, o conhecimento das variáveis meteorológicas é um passo importante para a elaboração de programas de prevenção e de combate aos incêndios em vegetação. A partir da análise climática, é possível determinar os períodos de maior probabilidade de ocorrências, facilitando a adoção de medidas de prevenção, a estimativa da logística para o combate e de danos causados pelo fogo ao ambiente. Entretanto, salienta-se que não basta que os fatores diretamente associados à ocorrência dos incêndios em vegetação estejam favoráveis, para que um incêndio ocorra é necessária uma fonte de ignição para dar início ao processo da combustão.

Por entender-se que a associação de vários fatores tem mais relação com as ocorrências de incêndios do que um fator isolado, além do caráter acumulativo das influências dos mesmos, analisou-se também os índices de perigo de incêndios encontrados na literatura (Sampaio, 1991 e Nunes, 2005). Sendo assim, o objetivo deste trabalho é, além da determinação dos elementos climáticos que mais se relacionam com os incêndios, bem como o comportamento acumulativo dos mesmos em relação à quantidade de ocorrências diárias, analisar a eficiência de índices de predição de incêndios, definindo o melhor horário de coleta dos dados utilizados nos mesmos (13:00 ou 15:00 horas) e a eficiência da utilização dos índices durante épocas diferentes no ano.

\section{DADOS E METODOLOGIA}

Para a realização deste estudo, foram utilizados os dados das ocorrências de incêndios em vegetação e os valores referentes aos elementos meteorológicos: umidade relativa do ar média (UR média), umidade relativa do ar das 13:00 e das 15:00 horas (UR ${ }_{13}$ e UR ${ }_{15}$, respectivamente), velocidade do vento (vento $\mathrm{m} / \mathrm{s}$ ), precipitação, evaporação, insolação, temperatura do ar média $\left(\mathrm{T}^{\circ} \mathrm{C}\right.$ média) e temperaturas do ar medidas às 13:00 e às 15:00 horas $\left(\mathrm{T}^{\circ} \mathrm{C}_{13} \mathrm{e} \mathrm{T}^{\circ} \mathrm{C}_{15}\right)$, coletados no município de Juiz de Fora (MG) pelo Laboratório de Climatologia e Análise Ambiental (LabCAA) da Universidade Federal de Juiz de Fora (UFJF), no período de 1995 à 2004.

A partir das variáveis disponíveis foram construídas as seguintes variáveis:

- média da umidade relativa do ar de dias anteriores a cada dia da série, nas seguintes situações: véspera (UR média1), de dois dias (UR média2), três dias (UR média3), quatro dias (UR média4), cinco dias (UR média5) e de dez dias (UR média10);

- precipitação total diária de dias anteriores a cada dia da série, nas seguintes situações: da véspera (Precipitação1), de dois dias (Precipitação2), três dias (Precipitação3), quatro dias (Precipitação4), cinco dias (Precipitação5) e de dez dias (Precipitação10);

- diferença entre a precipitação e a evaporação do dia (P-EVAP) e de dias anteriores a cada dia da série, nas seguintes situações: da véspera (P-EVAP1), de dois dias (P-EVAP2), três dias (P-EVAP3), quatro dias (P-EVAP4), cinco dias (P-EVAP5) e de dez dias (P-EVAP10);

- evaporação total diária de dias anteriores a cada dia da série, nas seguintes situações: da véspera (Evaporação1), de dois dias (Evaporação2), três dias (Evaporação3), quatro dias (Evaporação4), cinco dias (Evaporação5) e de dez dias (Evaporação10);

- insolação total diária de dias anteriores a cada dia da série, nas seguintes situações: da véspera (Insolação1), de dois dias (Insolação2), três dias (Insolação3), quatro dias (Insolação4), cinco dias (Insolação5) e de dez dias (Insolação10);

- temperatura do ponto de orvalho de cada dia da série, determinada pela Equação 1:

$$
\text { P.O. }=\sqrt[8]{\frac{\mathrm{UR}}{100}} *[112+(0,9 * \mathrm{~T})]+(0,1 * \mathrm{~T})-112
$$

sendo: P.O. a temperatura do ponto de orvalho, UR a umidade relativa do ar, em \% e T a temperatura do ar, em ${ }^{\circ} \mathrm{C}$ (Torres et al., 2008).

- pressão real de vapor de cada dia da série, determinada pela equação 2 :

$$
e=E^{\prime}-C P z\left(T-T^{\prime}\right)
$$

sendo: e a pressão real de vapor, em mmHg; E' a pressão máxima de vapor d'água para a temperatura T', $\mathrm{C}$ a constante psicrométrica: $\mathrm{C}=0,0008$ sem ventilação forçada e $\mathrm{C}=0,0006$ 
com ventilação; Pz a pressão atmosférica em $\mathrm{mmHg}$; T a temperatura do ar (bulbo seco), em ${ }^{\circ} \mathrm{C}$ e T' a temperatura do bulbo úmido, em ${ }^{\circ} \mathrm{C}$ (Torres et al., 2008).

- pressão de saturação de cada dia da série, determinada peça pressão máxima de vapor definida pela Equação 3:

$$
\mathrm{E}_{\mathrm{T}}=4,58 \times 10^{(7,5 \mathrm{~T} / 237,3+\mathrm{T})}
$$

sendo: $\mathrm{E}_{\mathrm{T}}$ a pressão máxima de vapor d'água na temperatura $\mathrm{T}$, em mmHg; $\mathrm{T}$ a temperatura do ar, em ${ }^{\circ} \mathrm{C}$ (Torres et al., 2008)

- déficit de saturação de cada dia da série, calculado através da Equação 4:

$$
\mathrm{d}=\mathrm{E}(1-\underline{\mathrm{H}})
$$

sendo: d o déficit de saturação do ar, em milibares; E a pressão máxima de vapor d'água, em milibares; $\mathrm{H}$ a umidade relativa do ar, em \% (Torres et al., 2008)

A correlação entre os elementos meteorológicos e as ocorrências de incêndios em vegetação, foi determinada através do Coeficiente de Correlação Linear de Pearson (r) através do software Statistica 7 (StatSoft), para cada um em relação ao número de ocorrências de cada dia da série.

Para a análise da eficiência de índices de predição foram utilizados: o Índice de Nesterov com temperaturas medidas às 13:00 e às 15:00 horas $\left(\right.$ Nesterov $_{13}$ e Nesterov $\left._{15}\right)$; Índice Logarítmico de Telicyn com temperaturas medidas às 13:00 e às 15:00 horas $\left(\right.$ Telicyn $_{13}$ e Telicyn $\left.{ }_{15}\right)$; Fórmula de Monte Alegre (FMA) com umidades relativas do ar medidas às 13:00 e às 15:00 horas $\left(\mathrm{FMA}_{13}\right.$ e $\left.\mathrm{FMA}_{15}\right)$; e os Índices acumulativos de precipitação - evaporação (P-EVAP) e da divisão da evaporação pela precipitação (EVAP/P) ambos sugeridos por Sampaio (1991). Os índices foram calculados da seguinte forma: (a) FMA

$$
\mathrm{FMA}=\sum_{\mathrm{i}=1}^{\mathrm{n}}(100 / \mathrm{Hi})
$$

sendo: FMA a Fórmula de Monte Alegre, $\mathrm{H}$ a umidade relativa do ar $(\%)$, medida às 13:00 e 15:00 horas, e $n=$ número de dias sem chuva (Torres et al., 2008).

Sendo acumulativo, o índice está sujeito às restrições de precipitação, como mostra a Tabela 1:

\section{(b) Índice Logarítmico do Telicyn (I)}

$$
I=\sum_{i=1}^{n} \log (t i-r i)
$$

sendo: I o índice de Telicyn, $\mathrm{t}$ a temperatura do $\operatorname{ar}$ em ${ }^{\circ} \mathrm{C}$ medida às 13:00 e às 15:00 horas, $r$ a temperatura do ponto de orvalho, em ${ }^{\circ} \mathrm{C}$, e log o logaritmo na base 10 (Torres et al., 2008).

Restrição do índice: sempre que ocorrer uma precipitação igual ou superior a 2,5 mm, abandonar a somatória e recomeçar o cálculo no dia seguinte, ou quando a chuva cessar. No(s) dia(s) de chuva o índice é igual a zero.

\section{(c) Índice de Nesterov (G)

$$
\mathrm{G}=\sum_{\mathrm{i}=1} \mathrm{di} \cdot \mathrm{ti}
$$

sendo: d o déficit de saturação do ar, em milibares; $t$ a temperatura do ar em ${ }^{\circ} \mathrm{C}$ medida às 13:00 e as 15:00 horas (Torres et al., 2008).

No índice de Nesterov, a continuidade da somatória é limitada pela ocorrência de precipitações de acordo com a Tabela 2.

Tabela 1 - Modificação no cálculo da FMA de acordo com a precipitação.

\begin{tabular}{ll}
\hline \hline \multicolumn{1}{c}{ mm de chuva no dia } & \multicolumn{1}{c}{ Modificação no cálculo } \\
\hline \hline$<2,4$ & Nenhuma \\
2,5 a 4,9 & $\begin{array}{l}\text { Abater } 30 \% \text { na FMA calculada na véspera e somar } \\
(100 / \mathrm{H}) \text { do dia }\end{array}$ \\
5,0 a 9,9 & $\begin{array}{l}\text { Abater } 60 \% \text { na FMA calculada na véspera e somar } \\
(100 / \mathrm{H}) \text { do dia }\end{array}$ \\
10,0 a 12,9 & $\begin{array}{l}\text { Abater } 80 \% \text { na FMA calculada na véspera e somar } \\
(100 / \mathrm{H}) \text { do dia } \\
>12,9\end{array}$ \\
\hline \hline
\end{tabular}




\section{(d) P-EVAP}

O índice acumulativo P-EVAP, proposto por Sampaio (1991), relaciona a diferença entre a precipitação (P) e a evaporação (EVAP), ambas medidas diariamente, em mm. O índice utilizou as restrições do índice de Nesterov (Tabela 2), sugerido pelo autor.

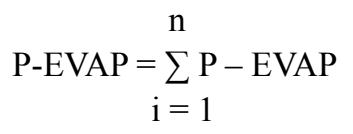

\section{(e) EVAP/P}

O índice EVAP/P(Sampaio, 1991) também é acumulativo e relaciona a divisão da evaporação pela precipitação, ambas as medidas diariamente em mm (Equação 9). Para seu cálculo foram utilizadas as seguintes restrições (Tabela 3 ).

$$
\mathrm{EVAP} / \mathrm{P}=\sum_{\mathrm{I}=1 \mathrm{EVAP}}^{\mathrm{E}}
$$

Para comparar os modelos, foi utilizado o método conhecido como Skill score (SS) (Sampaio, 1999; Torres, et al., 2008), que se baseia em uma tabela de contingência que contém os valores observados e os valores previstos para um evento em uma população. O SS é a razão da diferença entre os acertos na previsão $(\mathrm{G})$ e o número esperado de acertos $(\mathrm{H})$ e a diferença entre o numero de dias observados $(\mathrm{N})$ e o número de dias com previsão de acertos. A Tabela 4 ilustra como são realizados os cálculos para se obter o Skill score

As variáveis necessárias para a realização dos cálculos são:

Tabela 2 - Modificação no cálculo da $\mathrm{G}$ de acordo com a precipitação.

\begin{tabular}{ll}
\hline \hline \multicolumn{1}{c}{ mm de chuva no dia } & \multicolumn{1}{c}{ Modificação no cálculo } \\
\hline \hline$<2,4$ & Nenhuma \\
2,5 a 4,9 & $\begin{array}{l}\text { Abater } 30 \% \text { na FMA calculada na véspera e somar } \\
(100 / \mathrm{H}) \text { do dia }\end{array}$ \\
5,0 a 9,9 & $\begin{array}{l}\text { Abater } 60 \% \text { na FMA calculada na véspera e somar } \\
(100 / \mathrm{H}) \text { do dia }\end{array}$ \\
10,0 a 12,9 & $\begin{array}{l}\text { Abater } 80 \% \text { na FMA calculada na véspera e somar } \\
(100 / \mathrm{H}) \text { do dia }\end{array}$ \\
$>12,9$ & $\begin{array}{l}\text { Interromper o cálculo (FMA }=0), \text { recomeçando a somatória } \\
\text { no dia seguinte ou quando a chuva cessar }\end{array}$ \\
\hline \hline
\end{tabular}

$\mathrm{N}$ - Número total de observações. $\mathrm{N}=\mathrm{a}+\mathrm{b}+\mathrm{c}+\mathrm{d}$;

$\mathrm{G}$ - Número de acertos na previsão. $\mathrm{G}=\mathrm{a}+\mathrm{d}$;

$\mathrm{p}$ - Probabilidade de ter pelo menos um evento por dia. $\mathrm{p}=$ $\mathrm{N} 1 / \mathrm{N}$

$\mathrm{q}$ - Probabilidade de exceder $\mathrm{o}$ valor limite do índice. $\mathrm{q}=\mathrm{N} 2 / \mathrm{N}$ $\mathrm{H}$ - Número esperado de acertos. $\mathrm{H}=\mathrm{N} *(1-\mathrm{p}) *(1-\mathrm{q})+$ $\mathrm{N} * \mathrm{p} * \mathrm{q}$;

$\mathrm{SS}$ - Skill score. $\mathrm{SS}=(\mathrm{G}-\mathrm{H}) /(\mathrm{N}-\mathrm{H})$;

PS - Porcentagem de sucesso. PS $=\mathrm{G} / \mathrm{N}$;

Acerto nas previsões de ocorrências de incêndios $=\mathrm{a} / \mathrm{N} 2$;

Acerto nas previsões de não ocorrências = d / N4 .

Para se determinar o desempenho dos índices, foi necessário definir o limite que acusava e que não acusava a ocorrência de incêndio para cada um. Para tanto, considerouse que os índices não indicavam perigo de ocorrências de incêndios sempre que o valor calculado fosse menor que o limite inferior da classe de perigo, classificada como grau médio dos respectivos índices, e que estes indicavam perigo de ocorrências sempre que o valor dos índices era superior ao referido limite (Sampaio, 1999), este mecanismo, elimina da série os dias em que a probabilidade de ocorrências foi relativamente baixa, a inclusão dos mesmos implicaria em valores mais baixos de eficiência dos índices. Os valores limites acima dos quais foi considerado perigo de ocorrências foram: Nesterov $\geq 501$; Telicyn $\geq 3,6 ;$ FMA $\geq 3,1 ;$ P-EVAP $\leq 30,1$ e EVAP/P $\geq 20,1$ (Sampaio, 1991).

Os resultados foram comparados de acordo com 3 períodos: ano inteiro (janeiro-dezembro); estação normal do fogo (junho-outubro) e fora da estação normal do fogo (novembromaio), ambos determinados por Torres et al (2008).

\section{RESULTADOS}

Observa-se, na Tabela 5, que a correlação entre a variável resposta e suas preditoras para os dados diários é fraca. A variável explicativa que mais se correlaciona com o número de 
ocorrências, é a umidade relativa medida às 15:00 horas (UR 15), onde se obteve uma correlação $r=-0,4843$, seguida por $\mathrm{UR}_{13}$, UR média e déficit de saturação.

Os resultados foram similares aos encontrados por Soares e Paez (1974) para a região centro paranaense, que encontraram correlações importantes, sobretudo entre a umidade relativa e o déficit de saturação e baixa correlação para a temperatura do ar.

$\mathrm{O}$ único elemento que apresentou correlação não significativa foi a velocidade do vento, isto pode ser explicado pelo período de maior movimentação vertical e horizontal do ar que se concentra no verão, estação de menor número de incêndios; por outro lado, o inverno, caracterizado por menores velocidades do vento, apresenta maior concentração de ocorrências. O mesmo acontece com os coeficientes mais baixos das temperaturas (média, das 13:00 e das 15:00 horas), a variação sazonal das mesmas tende a mascarar sua relação com o fenômeno. Os resultados não implicam em uma insignificância da velocidade do vento ou da temperatura sobre os incêndios, e sim, que para se analisar sua influência deve-se buscar métodos mais adequados de análise.

De acordo com os resultados, os dados quando medidos às 15:00 horas $\left(\mathrm{UR}_{15}\right.$ e $\left.\mathrm{T}^{\circ} \mathrm{C}_{15}\right)$ têm maior coeficiente de correlação do que os valores médios (UR média e $\mathrm{T}^{\circ} \mathrm{C}$ média) e os mensurados às 13:00 horas $\left(\mathrm{UR}_{13}\right.$ e $\left.\mathrm{T}^{\circ} \mathrm{C}_{13}\right)$. Podendo ser explicado pelo horário em que é observado o maior valor da temperatura diária na cidade que ocorre por volta das 15:00 horas, obtendo com isso, o menor valor diário da umidade relativa do ar neste horário, de acordo com os dados obtidos. Este fato é responsável pelo pico do número de ocorrências, no município de Juiz de Fora, próximo ao horário das 15:00 horas. O mesmo resultado não foi compartilhado por Jacobi (2007), que em estudo sobre as ocorrências de incêndios em vegetação em Santa Maria (RS) encontrou um coeficiente maior para a UR média $(-0,41)$ em comparação com a da $\operatorname{UR}_{15}(-0,32)$, mostrando variações no comportamento dos incêndios de acordo com a localização da área estudada.

Os dados apontam ainda, para a importância da influência dos elementos meteorológicos sobre a umidade do material combustível. De acordo com Nunes et al. (2005), a umidade do material combustível expressa a porcentagem de água que ele contém, em relação ao seu peso seco. A primeira influência da umidade na combustão do material florestal é a necessidade da grande quantidade de energia requerida para transformar em vapor a água existente no combustível. Isso representa uma redução na quantidade de calor disponível para a combustão propriamente dita. A UR, déficit de saturação, evaporação e insolação atuam diretamente sobre a quantidade de umidade no combustível e estão entre os maiores índices de correlação. Observa-se, também, que os dados de precipitação e P-EVAP têm maior correlação quando acumulados, enquanto que UR, evaporação e insolação são mais eficientes quando analisados no dia da ocorrência.

Tabela 3 - Restrição do índice EVAP/P.

\begin{tabular}{ll}
\hline \hline \multicolumn{1}{c}{ mm de chuva no dia } & \multicolumn{1}{c}{ Modificação no cálculo } \\
\hline \hline$<2,0$ & $\begin{array}{l}\text { Nenhuma } \\
\text { Abater } 25 \% \text { no valor de G calculado na véspera e somar } \\
\text { (d.t) do dia }\end{array}$ \\
5,1 a 5,0 & $\begin{array}{l}\text { Abater } 50 \% \text { no valor de } \mathrm{G} \text { calculado na véspera e somar } \\
(\text { d.t }) \text { do dia } \\
8,1 \text { a } 10,0\end{array}$ \\
$\begin{array}{l}\text { Abandonar a somatória anterior e recomeçar novo cálculo, } \\
\text { isto é, } \mathrm{G}=(\text { d.t) do dia } \\
\text { Interromper o cálculo }(\mathrm{G}=0) \text {, recomeçando a somatória no } \\
\text { dia seguinte ou quando a chuva cessar. }\end{array}$ \\
\hline \hline
\end{tabular}

Fonte: NUNES (2005)

Tabela 4 - Tabela de contingência do Skill Score

\begin{tabular}{|c|c|}
\hline mm de chuva no dia & Modificação no cálculo \\
\hline$<1$ & Não entra no cálculo \\
\hline $1-15$ & $\begin{array}{l}\text { Dividir a EVAP/P da véspera pela chuva do } \\
\text { dia }\end{array}$ \\
\hline$>15$ & $\begin{array}{l}\text { Interromper o cálculo, recomeçando no dia } \\
\text { seguinte ou quando a chuva cessar. No dia da } \\
\text { chuva } E V A P / P=0,00\end{array}$ \\
\hline
\end{tabular}


Esta maior correlação dos dados quando acumulados está relacionada ao tempo de resposta do ambiente às condições atmosféricas, os valores da precipitação não interferem imediatamente na probabilidade de ocorrências de incêndios, sendo necessário um intervalo maior de tempo para a observação de sua influência (Torres et al., 2008).

De acordo com a Tabela 6 , observa-se que a quantidade de ocorrências está intimamente relacionada à quantidade de precipitação no dia da ocorrência, sendo que $97 \%$ dos incêndios ocorreram em dias com precipitação menor que $3 \mathrm{~mm}$. Contudo, a porcentagem de dias com ocorrências melhor se relaciona com o acúmulo da precipitação, onde em $79 \%$ dos dias sem chuva nos 5 dias anteriores ocorreram incêndios. Nos $52 \%$ dos dias com precipitação menor que $3 \mathrm{~mm}$ (Tabela 6) que concentram 97\% do total de ocorrências, há uma diferença entre outros elementos climáticos em relação aos $48 \%$ destes dias sem ocorrências. De acordo com a Tabela 7, observa-se que apesar do mesmo índice de precipitação, a temperatura das 15:00 horas foi $1^{\circ} \mathrm{C}$ superior,

Tabela 5 - Correlação linear de Pearson (r) entre o número de ocorrências de incêndios e elementos meteorológicos diários.

\begin{tabular}{lccc}
\hline \hline \multirow{2}{*}{ Previsto } & \multicolumn{2}{c}{ Observado } & \multirow{2}{*}{ Total previsto } \\
\cline { 2 - 3 } & Incêndios & Não Incêndios & \\
\hline \hline Incêndios & $\mathrm{a}$ & $\mathrm{b}$ & $\mathrm{N} 2=\mathrm{a}+\mathrm{b}$ \\
Não Incêndios & $\mathrm{c}$ & $\mathrm{d}$ & $\mathrm{N} 4=\mathrm{c}+\mathrm{d}$ \\
Total Observado & $\mathrm{N} 1=\mathrm{a}+\mathrm{c}$ & $\mathrm{N} 3=\mathrm{b}+\mathrm{d}$ & $\mathrm{N}=\mathrm{a}+\mathrm{b}+\mathrm{c}+\mathrm{d}$ \\
\hline \hline
\end{tabular}

Fonte: NUNES (2005)

Tabela 6 - Porcentagem de ocorrências e de dias com ocorrências de acordo com a quantidade e o acúmulo de precipitação.

\begin{tabular}{|c|c|c|c|}
\hline Elementos & $\mathrm{r}^{*}$ & Elementos & $\mathrm{r}^{*}$ \\
\hline $\mathrm{UR}_{15}$ & $-0,4843$ & Déficit de Saturação & 0,4446 \\
\hline $\mathrm{UR}_{13}$ & $-0,4732$ & Evaporação & 0,4056 \\
\hline UR média & $-0,4671$ & Insolação & 0,3578 \\
\hline UR médial & $-0,4324$ & Evaporação2 & 0,3555 \\
\hline UR média2 & $-0,4231$ & Evaporação3 & 0,3527 \\
\hline UR média3 & $-0,4131$ & Evaporação4 & 0,3452 \\
\hline UR média4 & $-0,4034$ & Insolação4 & 0,3451 \\
\hline UR média5 & $-0,392$ & Insolação5 & 0,3446 \\
\hline Ponto de Orvalho & $-0,3567$ & Insolação10 & 0,3429 \\
\hline Pressão Real & $-0,3554$ & Evaporação5 & 0,341 \\
\hline UR médial0 & $-0,3417$ & Insolação3 & 0,3404 \\
\hline Precipitação10 & $-0,3049$ & Insolação2 & 0,3288 \\
\hline P-EVAP10 & $-0,2936$ & Evaporação1 & 0,3216 \\
\hline Precipitação5 & $-0,2821$ & Evaporação10 & 0,3148 \\
\hline Precipitação4 & $-0,2743$ & Insolaçãol & 0,3038 \\
\hline Precipitação3 & $-0,2598$ & $\mathrm{~T}^{\circ} \mathrm{C}_{15}$ & 0,1829 \\
\hline Precipitação2 & $-0,2397$ & Pressão de Saturação & 0,1814 \\
\hline P-EVAP5 & $-0,2115$ & $\mathrm{~T}^{\circ} \mathrm{C}_{13}$ & 0,1326 \\
\hline P-EVAP4 & $-0,201$ & $\mathrm{~T}^{\circ} \mathrm{C}$ média & 0,0432 \\
\hline Precipitação & $-0,1999$ & & \\
\hline P-EVAP3 & $-0,1934$ & & \\
\hline Precipitação1 & $-0,1913$ & & \\
\hline P-EVAP2 & $-0,174$ & & \\
\hline P-EVAP1 & $-0,1411$ & & \\
\hline P-EVAP & $-0,1291$ & & \\
\hline Vento $\mathrm{m} / \mathrm{s}$ & $-0,0115^{* *}$ & & \\
\hline
\end{tabular}

* Coeficiente de Correlação de Pearson com nível de significância de 5\%

** não significativo 
a evaporação foi $1 \mathrm{~mm}$ maior, a insolação foi 2 horas a mais e a umidade relativa do ar das 15:00 horas foi $12 \%$ menor nos dias em que houveram incêndios, comparados com os dias de mesma precipitação sem ocorrências observadas. A quantidade de ocorrências no dia parece também estar relacionada a estes elementos, quanto maior o número de ocorrências no dia, maior a temperatura, evaporação e insolação e menor umidade relativa do ar das 15:00 horas no dia das ocorrências, onde nos dias em que houve mais de 4 incêndios, a temperatura foi maior em $2^{\circ} \mathrm{C}$, a evaporação em $2 \mathrm{~mm}$, a insolação diária em 3 horas e a umidade relativa do ar das 15:00 horas menor em 19\% em comparação com os dias sem ocorrências observadas.

Uma comparação similar pode ser feita no período de maior porcentagem de dias com ocorrências. Como já observado na Tabela 6 , em 79\% dos dias sem precipitação acumulada nos 5 dias anteriores foi observada pelo menos uma ocorrência. Nos 21\% restantes destes dias (em que não foram observados incêndios), de acordo com a Tabela 8 a temperatura das 15:00 horas foi $1^{\circ} \mathrm{C}$ menor, a evaporação $0,7 \mathrm{~mm}$ menor, a insolação 1,7 hora menor e a umidade relativa do ar 7,6\% maior em relação aos dias com incêndios observados. A quantidade de ocorrências no dia também se relaciona com estes outros elementos climáticos, a temperatura foi $1,9^{\circ} \mathrm{C}$ maior, a evaporação foi 1,6 $\mathrm{mm}$ maior, a insolação 2,7 horas maior e a umidade relativa do ar 10,4\% menor nos dias com mais de 4 incêndios observados em relação aos dias sem ocorrências.

Quanto à umidade relativa do ar das 15:00 horas, de acordo com a Tabela 9, em todos os dias em que a mesma foi inferior à 36\%, ocorreram incêndios e neste período a média de ocorrências por dia foi de 6,4 , concentrando $12 \%$ de todas as ocorrências. A maior parte das ocorrências (91\%) aconteceu quando a umidade foi inferior à 70\%, sendo que 57\% destes dias apresentaram pelo menos um registro com média de 1,7 ocorrência ao dia. Por outro lado, acima de $70 \%$ de umidade a média de ocorrências por dia foi de 0,27 , apresentando $14 \%$ de dias com ocorrência e concentrando apenas $8 \%$ do total das mesmas.

A Tabela 10 apresenta a relação do acúmulo da diferença entre a precipitação e a evaporação e a quantidade das ocorrências, bem como, a porcentagem de dias com ocorrências. De acordo com os resultados, $96 \%$ das ocorrências foram observadas em dias em que a evaporação foi maior que a precipitação, $54 \%$ dos dias nestas condições apresentaram pelo menos 1

Tabela 7 - Comparação dos valores dos elementos climáticos de acordo com a quantidade de ocorrências em dias com precipitação acumulada menor que $3 \mathrm{~mm}$.

\begin{tabular}{lcccccccc}
\hline \hline \multirow{2}{*}{ Precipitação } & \multicolumn{2}{c}{$<3 \mathrm{~mm}$} & \multicolumn{2}{c}{$<2 \mathrm{~mm}$} & \multicolumn{2}{c}{$<1 \mathrm{~mm}$} & \multicolumn{2}{c}{$0 \mathrm{~mm}$} \\
\cline { 2 - 8 } & ocor & dias & ocor & dias & ocor & dias & ocor & dias \\
\hline \hline Acumulada no dia & $97 \%$ & $52 \%$ & $97 \%$ & $53 \%$ & $95 \%$ & $56 \%$ & $93 \%$ & $57 \%$ \\
Acumulada na véspera & $93 \%$ & $56 \%$ & $93 \%$ & $59 \%$ & $90 \%$ & $63 \%$ & $87 \%$ & $65 \%$ \\
Acumulada em 2 dias & $90 \%$ & $62 \%$ & $90 \%$ & $64 \%$ & $86 \%$ & $69 \%$ & $81 \%$ & $71 \%$ \\
Acumulada em 3 dias & $85 \%$ & $66 \%$ & $84 \%$ & $68 \%$ & $80 \%$ & $72 \%$ & $74 \%$ & $74 \%$ \\
Acumulada em 4 dias & $81 \%$ & $69 \%$ & $80 \%$ & $71 \%$ & $75 \%$ & $75 \%$ & $68 \%$ & $77 \%$ \\
Acumulada em 5 dias & $77 \%$ & $72 \%$ & $76 \%$ & $74 \%$ & $68 \%$ & $78 \%$ & $61 \%$ & $79 \%$ \\
Acumulada em 10 dias & $60 \%$ & $73 \%$ & $59 \%$ & $76 \%$ & $44 \%$ & $75 \%$ & $37 \%$ & $77 \%$ \\
\hline \hline
\end{tabular}

Tabela 8 - Comparação dos valores dos elementos climáticos de acordo com a quantidade de ocorrências em dias sem chuva acumulada nos 5 dias anteriores.

\begin{tabular}{lcccc}
\hline \hline \multirow{2}{*}{ Dias com precipitação $<3 \mathrm{~mm}$} & \multicolumn{4}{c}{ Média } \\
\cline { 2 - 5 } & $\mathrm{T}^{\circ} \mathrm{C}_{15}$ & Evaporação & Insolação & UR\% 15 \\
\hline \hline Dias sem ocorrências & 23 & 3 & 5 & 69 \\
Dias com ocorrências & 24 & 4 & 7 & 57 \\
Dias com 1 ocorrência & 23 & 3 & 6 & 62 \\
Dias com 2 ocorrências & 24 & 4 & 7 & 59 \\
Dias com 3 ocorrências & 25 & 4 & 8 & 55 \\
Dias com mais de 4 ocorrências & 25 & 5 & 8 & 50 \\
\hline \hline
\end{tabular}


incêndio. Por outro lado, quando P-EVAP acumulada em 10 dias anteriores foi negativo (evaporação > precipitação) $64 \%$ dos dias apresentaram pelo menos 1 ocorrência, concentrando $83 \%$ de todas as ocorrências neste período.

\section{1 Índices de Risco}

Analisando-se o período inteiro (janeiro a dezembro), a Tabela 11 mostra a porcentagem de acerto das previsões de ocorrências dos Índices. Observa-se que o Índice P-EVAP foi o mais eficiente nas previsões de ocorrências de incêndios, seguido ordenadamente pelos Índices EVAP/P, Telicyn ${ }_{13}$, Telicyn ${ }_{15}$, Nesterov $_{13}, \mathrm{FMA}_{15}$, Nesterov $_{15}$, e em último $\mathrm{FMA}_{13}$.

Com relação ao acerto das previsões de não ocorrência de incêndios, a Tabela 11 aponta a FMA 15 como mais eficiente, em segundo lugar $\mathrm{FMA}_{13}$, seguidas por Nesterov ${ }_{15}$, Nesterov ${ }_{13}$, Telicyn $_{15}$, EVAP/P, P-EVAP e Telicyn 13 . A porcentagem de sucesso geral das previsões coloca em primeiro lugar o índice EVAP/P com $78 \%$ de sucesso, seguido de Telicyn ${ }_{15}$ com $76 \%$, P-EVAP com $75 \%$, Telicyn 13 com $73 \%, \mathrm{FMA}_{15}$ com $70 \%$, Nesterov 15 com $69 \%$, FMA $_{13}$ com $68 \%$ e Nesterov 13 com $66 \%$ de sucesso nas previsões. O Skill score (Tabela 11), ou desempenho médio dos índices de perigo de incêndios, acompanha o sucesso nas previsões de ocorrências, mantendo a mesma ordem de eficiência.

Os resultados apontam para uma maior eficiência dos dados, tanto de temperatura do ar quanto de umidade relativa do ar, quando medidos às 15:00. O mesmo não foi registrado em pesquisas para o Estado do Paraná (Soares, 1972, 1998; Nunes, 2005; Nunes et al., 2005, 2006, 2007 e Sampaio, 1991, 1999) que aponta a medição realizada às $13: 00$ como a mais eficiente. Este fato pode ser explicado pelo horário de maior concentração de ocorrência de incêndios em Juiz de Fora, como tendo seu pico entre 15 e 15:59 horas (Torres et al., 2008). Outro fator é a medição da umidade relativa e da temperatura realizada às 15:00, tendo maior índice de correlação linear com a quantidade de ocorrências quando comparada à medição das 13:00. Determinado o horário de realização das medições mais eficientes como sendo o das 15:00 horas, a comparação da eficiência dos índices, de acordo com os outros dois períodos, levou em consideração apenas as medições realizadas neste horário.

Dentro da estação normal do fogo, que vai de junho a outubro (Torres et al., 2008), o índice que apresentou melhor desempenho nas previsões de ocorrências de incêndios de acordo com a Tabela 12 foi o de Telicyn com $84,7 \%$ de acertos,

Tabela 9 - Número de ocorrências, porcentagem de dias com ocorrências e número de ocorrências por dia de acordo com a umidade relativa do ar das 15:00 horas.

\begin{tabular}{lcccc}
\hline \hline Sem chuva acumulada nos últimos 5 & \multicolumn{4}{c}{ Média } \\
\cline { 2 - 5 } \multicolumn{1}{c}{ dias } & $\mathrm{T}^{\circ} \mathrm{C}_{15}$ & Evaporação & Insolação & UR\% ${ }_{15}$ \\
\hline \hline Dias sem ocorrências & 23,1 & 3,4 & 5,3 & 64,4 \\
Dias com ocorrências & 24,1 & 4,1 & 7 & 56,8 \\
Dias com 1 ocorrência & 23 & 4 & 6 & 63 \\
Dias com 2 ocorrências & 23 & 4 & 7 & 60 \\
Dias com 3 ocorrências & 25 & 4 & 8 & 54 \\
Dias com mais de 4 ocorrências & 25 & 5 & 8 & 50 \\
\hline \hline
\end{tabular}

Tabela 10 - Porcentagem de ocorrências e de dias com ocorrências de acordo com a diferença entre precipitação e evaporação (P-EVAP) negativa acumulada.

\begin{tabular}{cccc}
\hline \hline UR & Ocorrências & $\%$ de dias com ocorrências & Ocorrências/dia \\
\hline \hline$>90 \%$ & $<1 \%$ & $4 \%$ & 0,1 \\
$>80 \%$ & $3 \%$ & $9 \%$ & 0,22 \\
$>70 \%$ & $8 \%$ & $14 \%$ & 0,27 \\
\hline$<70 \%$ & $91 \%$ & $57 \%$ & 1,7 \\
$<60 \%$ & $68 \%$ & $70 \%$ & 2,4 \\
$<50 \%$ & $38 \%$ & $80 \%$ & 3,8 \\
$<40 \%$ & $17 \%$ & $89 \%$ & 5,8 \\
$<36 \%$ & $12 \%$ & $100 \%$ & 6,4 \\
\hline \hline
\end{tabular}


Tabela 11 - Comparação entre os resultados dos índices durante o ano inteiro.

\begin{tabular}{lcc}
\hline \hline \multirow{2}{*}{\multicolumn{1}{c}{ P-EVAP }} & \multicolumn{2}{c}{ Negativo } \\
\cline { 2 - 3 } & Ocorrências & dias \\
\hline \hline Acumulada no dia & $96 \%$ & $54 \%$ \\
Acumulada na véspera & $95 \%$ & $57 \%$ \\
Acumulada em 2 dias & $93 \%$ & $58 \%$ \\
Acumulada em 3 dias & $91 \%$ & $60 \%$ \\
Acumulada em 4 dias & $89 \%$ & $60 \%$ \\
Acumulada em 5 dias & $88 \%$ & $61 \%$ \\
Acumulada em 10 dias & $83 \%$ & $64 \%$ \\
\hline \hline
\end{tabular}

Tabela 12 - Comparação entre os resultados dos índices durante a estação normal do fogo.

\begin{tabular}{lcccc}
\hline \hline \multirow{2}{*}{$\begin{array}{c}\text { Índices } \\
\text { (jan-dez) }\end{array}$} & \multicolumn{3}{c}{ Porcentagem de sucesso } & Skill score \\
\cline { 2 - 4 } & ocorrências & $\begin{array}{c}\text { Nas previsões de não } \\
\text { ocorrências }\end{array}$ & Geral & \\
\hline \hline FMA $_{13}$ & $56,4 \%$ & $89,6 \%$ & $68 \%$ & 0,388158 \\
FMA $_{15}$ & $58,2 \%$ & $89,9 \%$ & $70 \%$ & 0,420284 \\
Telicyn $_{13}$ & $72,3 \%$ & $73,7 \%$ & $73 \%$ & 0,460614 \\
Telicyn $_{15}$ & $70,2 \%$ & $80,6 \%$ & $76 \%$ & 0,511413 \\
Nesterov $_{13}$ & $59,7 \%$ & $81,5 \%$ & $66 \%$ & 0,330066 \\
Nesterov & $57,8 \%$ & $88,1 \%$ & $69 \%$ & 0,406493 \\
P-EVAP & $76,9 \%$ & $74,8 \%$ & $75 \%$ & 0,473404 \\
EVAP/P & $76,3 \%$ & $79,4 \%$ & $78 \%$ & 0,534623 \\
\hline \hline
\end{tabular}

seguido do EVAP/P com 84,2\%, P-EVAP com 82,9\%, Nesterov com 78,1\% e FMA com 76,7\%. Quanto à eficiência dos índices nas previsões de não ocorrências (Tabela 12), a FMA apresentou melhor desempenho com $85,3 \%$ de acertos, seguida do índice de Nesterov com 78,8\%, Telicyn com 66\%, EVAP/P com $58 \%$ e P-EVAP com $53,1 \%$. Os resultados da porcentagem de sucesso nas previsões (Tabela 12) apontam para um empate entre FMA, Nesterov e Telicyn em primeiro lugar com $78 \%$, seguidos do EVAP/P com $74 \%$ e P-EVAP com $70 \%$. Contudo, ao se analisar o Skill score (Tabela 12), o índice de Telicyn foi o mais eficiente dentro da estação normal do fogo, seguido do índice de Nesterov, EVAP/P, FMA e P-EVAP.

Com relação ao período fora da estação normal do fogo, de novembro a maio (Torres et al., 2008), observando-se a Tabela 13, o índice que apresentou maior porcentagem de sucesso nas previsões de ocorrências foi o P-EVAP com 56\% de acertos, seguido do EVAP/P com 54,2\%, Telicyn com 43,9\%, FMA com $35.3 \%$ e Nesterov com $34,5 \%$ de acertos. Analisandose a eficiência nas previsões de não ocorrências (Tabela 13), os índices que apresentaram melhor desempenho foram a FMA e Nesterov ambos com $90,9 \%$ e $90,7 \%$ de acertos, seguidos do índice de Telicyn com 85,4\%, EVAP/P com 84,3\% e P-EVAP com $82,4 \%$. A porcentagem de sucesso nas previsões (Tabela 13) coloca os índices de EVAP/P e P-EVAP em primeiro lugar com $79 \%$ de acertos, em segundo o índice de Telicyn com $75 \%$, terceiro a FMA com $63 \%$ e em quarto Nesterov com $62 \%$ de acertos. De acordo com os resultados do Skill score (Tabela 13), o índice EVAP/P foi o mais eficiente dentro do período fora da estação normal do fogo, seguido do índice de Telicyn P-EVAP, FMA e Nesterov.

A Tabela 14 apresenta um resumo do desempenho dos índices, considerando o cruzamento entre a época de estudo e o percentual de sucesso nas quatro situações (previsão de ocorrência, previsão de não ocorrência, percentual geral $e$ Skill score).

Pode ser observado, que para uma previsão geral o índice EVAP/P foi o mais eficiente durante o ano completo e fora da estação normal do fogo, empatado com o índice P-EVAP. O $\mathrm{FMA}_{15}$ se destacou com melhor desempenho para prever as não ocorrências de incêndios nos três períodos estudados, o $\mathrm{P}$ EVAP teve melhor desempenho para prever as ocorrências no ano completo e fora da estação normal do fogo; contudo, pelo 
Tabela 13 - Comparação entre os resultados dos índices fora da estação normal do fogo.

\begin{tabular}{|c|c|c|c|c|}
\hline \multirow{2}{*}{$\begin{array}{l}\text { Índices } \\
\text { (jun-out) }\end{array}$} & \multicolumn{3}{|c|}{ Porcentagem de sucesso } & \multirow[b]{2}{*}{ Skill score } \\
\hline & $\begin{array}{l}\text { Nas previsões de } \\
\text { ocorrências }\end{array}$ & $\begin{array}{c}\text { Nas previsões de não } \\
\text { ocorrências }\end{array}$ & Geral & \\
\hline $\mathrm{FMA}_{15}$ & $76,7 \%$ & $85,3 \%$ & $78 \%$ & 0,415685 \\
\hline Telicyn $_{15}$ & $84,7 \%$ & $66,0 \%$ & $78 \%$ & 0,506579 \\
\hline Nesterov $_{15}$ & $78,1 \%$ & $78,8 \%$ & $78 \%$ & 0,440762 \\
\hline P-EVAP & $82,9 \%$ & $53,1 \%$ & $70 \%$ & 0,3708 \\
\hline EVAP/P & $84,2 \%$ & $58,0 \%$ & $74 \%$ & 0,435262 \\
\hline
\end{tabular}

Tabela 14 - Desempenho dos índices estudados de acordo com a época do ano e com o percentual de sucesso.

\begin{tabular}{|c|c|c|c|c|}
\hline \multirow{2}{*}{$\begin{array}{l}\text { Índices } \\
\text { (nov-mai) }\end{array}$} & \multicolumn{3}{|c|}{ Porcentagem de sucesso } & \multirow[b]{2}{*}{ Skill score } \\
\hline & $\begin{array}{c}\text { Nas previsões de } \\
\text { ocorrências }\end{array}$ & $\begin{array}{c}\text { Nas previsões de não } \\
\text { ocorrências }\end{array}$ & Geral & \\
\hline $\mathrm{FMA}_{15}$ & $35,3 \%$ & $90,9 \%$ & $63 \%$ & 0,263373 \\
\hline Telicyn $_{15}$ & $43,9 \%$ & $85,4 \%$ & $75 \%$ & 0,30722 \\
\hline Nesterov $_{15}$ & $34,5 \%$ & $90,7 \%$ & $62 \%$ & 0,248733 \\
\hline P-EVAP & $56,0 \%$ & $82,4 \%$ & $79 \%$ & 0,2779 \\
\hline EVAP/P & $54,2 \%$ & $84,3 \%$ & $79 \%$ & 0,342076 \\
\hline
\end{tabular}

Skill score, o índice que mais se destacou foi o EVAP/P durante o ano completo e fora da estação normal do fogo.

\section{CONCLUSÕES}

De acordo com os resultados pode-se concluir que:

- a umidade relativa do ar medida às 15:00 $\mathrm{h}$, foi o elemento meteorológico que melhor se correlacionou com a quantidade diária de ocorrências de incêndios em vegetação no município de Juiz de Fora;

- a quantidade de ocorrências em dias com precipitação inferior a $3 \mathrm{~mm}$ ou que não apresentou chuvas nos últimos 5 dias, aumentou à medida em que houve um aumento da temperatura, da insolação e da evaporação e diminuição da umidade relativa do ar;

- 96\% dos incêndios ocorreram em dias em que a evaporação foi maior que a precipitação, e à medida que se aumentou o número de dias sem precipitação, maior foi o percentual de dias com pelo menos uma ocorrência;

- os baixos índices de correlação entre as ocorrências de incêndios e os elementos meteorológicos, indicaram a necessidade de incorporar mais de uma variável nos modelos preditivos, principalmente em se tratando de ambiente urbano que apresenta uma dinâmica de microclima diferente de ambientes rurais.
- a influência da velocidade do vento e da temperatura sobre as ocorrências não se mostraram eficazes isoladamente através da correlação linear, sugerindo a necessidade de estudos mais detalhados por meio da combinação de uma ou mais variáveis.

- os índices apresentaram maior eficiência quando utilizaram os dados de umidade relativa e temperatura mensurados às 15:00 horas;

- os índices estudados apresentaram maior percentual de acerto para as previsões de não ocorrência, considerando o período fora da estação normal do fogo;

- os índices apresentaram maior percentual de acerto para as previsões de ocorrências durante a estação normal do fogo;

- os índices que apresentaram melhor desempenho geral, foram EVAP/P para o ano completo; EVAP/P e P-EVAP para a época fora da estação normal do fogo e $\mathrm{FMA}_{15}$, Telicyn ${ }_{15} \mathrm{e}$ Nesterov $_{15}$ para a estação normal do fogo;

- o maior valor do Skill score foi obtido pelo índice EVAP/P, quando usado durante o ano completo, caracterizando este como o índice mais eficiente para a cidade de Juiz de Fora;

- é importante ressaltar que a condição de risco de incêndio, de acordo com as condições climáticas, não está relacionada à obrigatoriedade do episódio, e sim que o cenário climático torna propícia a ocorrência. É necessária a fonte de 
ignição, assim, mesmo em dias extremamente propícios, não são observadas ocorrências, pois não houve esta fonte, por outro lado, dias em que as condições climáticas são altamente desfavoráveis, contudo há a existência de fontes consideráveis de ignição, foram registradas algumas ocorrências.

\section{REFERÊNCIAS BIBLIOGRÁFICAS}

JACOBI, L. F. Queimadas acidentais em campo em Santa Maria - RS. 2007. 57 f. Tese (Doutorado em Agronomia) - Centro de Ciências Rurais, Universidade Federal de Santa Maria, Santa Maria, 2007.

NUNES, J. R. S. FMA+ - Um novo índice de perigo de incêndios florestais para o Estado do Paraná - Brasil. 2005. 150 f. Tese (Doutorado em Engenharia Florestal) - Setor de Ciências Agrárias, Universidade Federal do Paraná, Curitiba, 2005.

NUNES, J. R. S.; SOARES, R.V. e BATISTA, A.C. Estimativa da umidade relativa das 13:00 h, com base nos dados das 9:00 h e das 15:00 h, para o Estado do Paraná. Curitiba: Floresta, v.35 n.2, p.247-258. 2005.

NUNES, J.R. S.; SOARES, R.V.eBATISTA,A.C. Especificação de um sistema computacional integrado de controle de incêndios florestais. Curitiba: Floresta, v.36, n.2, p.201-211, 2006.
NUNES, J. R. S.; SOARES, R.V. e BATISTA, A.C. Ajuste da Fórmula de Monte Alegre Alterada - FMA+ para o estado do Paraná. Curitiba: Floresta, v.37, n.1, p.1-14, 2007.

SAMPAIO, O. B. Estudo comparativo de índices, para previsão de incêndios florestais, na região de Coronel Fabriciano, Minas Gerais. 1991. 88 f. Dissertação (Mestrado em Ciência Florestal) - Universidade Federal de Viçosa, Viçosa, 1991.

SAMPAIO, O. B. Análise da eficiência de quatro índices na previsão de incêndios florestais para a região de Agudos -SP. 1999. 157 f. Tese (Doutorado em Engenharia Florestal) - Setor de Ciências Agrárias, Universidade Federal do Paraná, Curitiba, 1999.

SOARES, R. V. Índice de perigo de incêndio. Curitiba: Floresta, v. 3, n. 3, p.19-40. 1972.

SOARES, R. V. Desempenho da "Fórmula de Monte Alegre" índice brasileiro de perigo de incêndios florestais. Lavras: Cerne, v.4, nº.1, p.87-99. 1998.

SOARES, R. V. e PAEZ, G. Correlations between some meteorological factor and the occurrence of forest fire in the central Paraná region of Brasil. Curitiba: Floresta, 4(2):5867, 1973. Forestry Abstracts, v.35, n.1, p.364, 1974.

TORRES, F. T. P. et al. Incêndios em vegetação na área urbana de Juiz de Fora - Minas Gerais. Ubá: Editora Geographica Consultoria, Estudos e Projetos Ambientais, 2008. 65p. 